\title{
VALORISATION OF AGRICULTURAL WASTE THROUGH PYROLYSIS IN THE PRODUCTION OF BIOCHAR
}

\author{
GENYR KAPPLER, Dr. | UNISINOS \\ CARLOS ALBERTO MENDES MORAES, Dr. | UNISINOS \\ LUÍS ANTÓNIO DA CRUZ TARELHO, Dr. | UA - PTG
}

\section{ABSTRACT}

Biochar is the carbon-rich material, produced from biogenic biomass under pyrolysis conditions, and is characterized by environmentally sustainable production, quality, and innovative uses. Agricultural-waste is an important source of plant biomass, and pyrolysis has been recognized as an efficient technology for converting this type of waste to obtain higher-value products. This work investigates the influence of pyrolysis operating conditions on the characteristics of the products. Three types of agricultural-waste obtained in agricultural industries (sugarcane bagasse-BCA, rice husk-CA and green coconut shell-CCV) were pyrolyzed in a horizontal, bench scale, fixed bed type reactor with electric heating. The operating conditions were set as: pyrolysis temperatures (350, 450 and 550 $\left.{ }^{\circ} \mathrm{C}\right)$, heating rates $\left(2,10\right.$ and $\left.30^{\circ} \mathrm{C} . \mathrm{min}-1\right), 30 \mathrm{~min}$ soaking time at the pyrolysis temperature, and a flow of $250 \mathrm{~cm} 3$. min-1 of N2 as the carrier gas. The samples of biomass and pyrolysis products were evaluated using gravimetric analysis, along with thermal, chemical, and physical analysis. The results showed that, in general, the pyrolysis temperature was the parameter with a dominant influence on the products yield. When the pyrolysis temperature increased from 350 to $550{ }^{\circ} \mathrm{C}$ and heating rate was $10^{\circ}$ C.min-1, the biochar yield of BCA decreased from 33.9 to $25.1 \mathrm{wt} \%$, that of CA decreased from 45.7 for $38.1 \mathrm{wt} \%$, and for CCV the yield decreased from 42.2 to $33.4 \mathrm{wt} \%$, on a dry basis. The TG curve shows that devolatilization is virtually completed at $350^{\circ} \mathrm{C}$. However, according to IBI standards, the biochar structure changed from thermochemically altered to thermochemically converted at higher temperatures. That has been observed through the $\mathrm{H}: \mathrm{C}$ molar ratios in the biochar samples, e.g., 0.73 at 450 ${ }^{\circ} \mathrm{C}, 0.61$ at $550{ }^{\circ} \mathrm{C}$ and 0.67 at $450{ }^{\circ} \mathrm{C}$ on BCA, CA and CCV, respectively. The FTIR results showed that the biochar samples from the three types of biomass produced at a temperature of $450^{\circ} \mathrm{C}$ have more aromatic- $\mathrm{C}$ compared to those produced at $350{ }^{\circ} \mathrm{C}$, which indicates an increase of recalcitrance with the increase in the pyrolysis temperature. Additionally, the increase in the pyrolysis temperature caused an increase in $\mathrm{pH}$ and a decrease in CTC. The SEM analysis showed that the biochar samples have a complex pore structure of different dimensions that consists of multiple interconnected networks with different shapes and arrangements. The energy available in the products was evaluated and the energy balance was carried out through a simulation on a specific basis in a continuous reactor to produce biochar. The simulation suggests that the combustion of the pyrolysis gases of the three types of biomass can generate the thermal energy necessary for the pyrolysis. After pyrolysis, 2.5 and $3.4 \mathrm{MJ} \mathrm{.} \mathrm{kg}^{-1}{ }_{\mathrm{BR}}$ bs of thermal energy remained, which is useful energy for, e. g., drying the biomass. The research showed the relevance of knowing the influence of operating conditions on the properties of the products. The energy balance can guide the development of technologies to scale the process. 
